\title{
Cutaneous Leishmaniasis: Revisited
}

\section{Neupane $\mathbf{S}^{1}$}

${ }^{1}$ Associate Professor, Department of Dermatology, Gandaki Medical College, Pokhara, Nepal.

L eishmaniasis is a vector borne disease, caused by protozoa of Leishmania species and transmitted by the bite of certain types of sandflies. The disease can present either as visceral, cutaneous or mucocutaneous forms with cutaneous leishmaniasis being the most common presentation. ${ }^{1}$ It causes chronic non-healing wound in the exposed parts. The end result of the healing of the wound is a permanent scar which can be a cause of disability. While the visceral form known as Kala-azar, has drawn a significant attention of policy makers and is towards elimination, cutaneous leishmaniasis is still an under-recognized and neglected disease. The first case of cutaneous leishmaniasis from Nepal was reported in $2006 .^{2}$ Soon after it was followed by a report of a case series of the same from Kathmandu. ${ }^{3}$ Once again, this issue highlights the importance of cutaneous leishmaniasis in our region by its larger caseloads in the mid-western region of Nepal. The work must be appreciated because of highlighting a neglected disease and for the effort that has been made to diagnose it in a resource limited setting with a minimally invasive technique like fine needle aspiration cytology. We hope that this issue will draw the attention of our policy makers to implement cutaneous leishmaniasis in the national guideline and to formulate a protocol for the effective management and control of the disease.

\section{References}

1. Alvar J, Velez ID, Bern C, Herrero M, Desjeux P, Cano J, Jannin J, den Boer M, WHO Leishmaniasis Control Team. Leishmaniasis worldwide and global estimates of its incidence. Plos one. 2012;7(5):e35671. https://doi.org/10.1371/ journal.pone.0035671
2. Pandey BD, Babu E, Thapa S, Thapa LB. First case of cutaneous leishmaniasis in Nepalese patient. Nepal Med Coll J. 2006;8(3):213-4.

3. Neupane S, Sharma P, Kumar A, Paudel U, Pokhrel DB. Cutaneous leishmaniasis: report of rare cases in Nepal. Nepal Med Coll J. 2008;10(1):64-7.

\footnotetext{
Address of Correspondence:

Dr. Saraswoti Neupane

Associate Professor

Department of Dermatology

Gandaki Medical College, Pokhara, Nepal.

E-mail: sarunpn@gmail.com
}

How to cite this article

Neupane S. Cutaneous Leishmaniasis: Revisited. Nepal Journal of Dermatology Venereology and Leprology. 2018;16(1):1-1. doi: http://dx.doi.org/10.3126/njdvl.v16i1.19396

\section{(c) (7)}

Licensed under CC BY 4.0 International License which permits use, distribution and reproduction in any medium, provided the original work is properly cited. 